1 Universidade Federal Fluminense (UFF),

Escola de Serviço Social, Programa de Estudos Pós-Graduados em Política Social - Niterói (RJ), Brasil.

lenauralobato@uol.com.br

2 Universidade Federal Fluminense (UFF), Escola de Serviço Social, Programa de Estudos Pós-Graduados em Política Social - Niterói (RJ), Brasil.

evangelinamartich@hotmail.com

3 Fundação Oswaldo Cruz (Fiocruz), Escola Politécnica de Saúde Joaquim Venâncio (EPSJV) - Rio de Janeiro (RJ), Brasil.

ingriddavilla@gmail.com

\section{Prefeitos eleitos, descentralização na saúde e os compromissos com o SUS}

\author{
Elected mayors, health decentralization and commitments with the \\ SUS
}

Lenaura de Vasconcelos Costa Lobato ${ }^{\mathbf{1}}$ Evangelina Martich $\mathbf{2}$, Ingrid D'avilla Freire Pereira ${ }^{\mathbf{3}}$

RESUMO O artigo analisa a municipalização na saúde por meio das proposições para a política de saúde de prefeitos eleitos no ano de 2012. Realizou-se análise documental das plataformas de governo dos então candidatos e de documentos oficiais da política e da gestão municipais de saúde - Relatórios das Conferências Municipais de Saúde e Planos Municipais de Saúde - de 24 municípios brasileiros nas cinco regiões do País. Os resultados indicam que os programas das candidaturas, em geral, incorporam a defesa do direito à saúde, embora principalmente através da ampliação da oferta de serviços médicos.

PALAVRAS-CHAVE Política de saúde; Descentralização; Governo local.

ABSTRACT The article analyzes the municipalization of health by means of propositions for health policy of mayors elected in the year 2012. Documentary analysis was carried out on the so candidates' government platforms and on official documents of the municipalities' health policy and management, i.e., Municipal Health Conferences Reports and Municipal Health Plans, of 24 municipalities in the five regions of the Country. The results indicate that the candidatures generally incorporate the defense of the right to health, although mainly through the increasing of medical services supply.

KEYWORDS Health policy; Decentralization; Local government. 


\section{Introdução}

O Brasil é uma federação de mais de um século e a dinâmica federativa sempre teve forte influência sobre o desenvolvimento do Estado e sua operação através de políticas públicas. A Constituição de 1988 definiu que a responsabilidade pela provisão da maioria dos serviços públicos, em especial os sociais, é comum aos três níveis de governo. Essa descentralização tem sido traduzida pelo componente da municipalização e faz parte das especificidades do desenho federativo brasileiro, uma vez que este incorporou os municípios, juntamente com os estados,

como partes integrantes da federação, refletindo uma longa tradição de autonomia municipal e de escasso controle dos estados sobre as questões locais. (SOUZA, 2005, P. 110).

À tradicional autonomia do nível local agregou-se um papel inédito e central dos municípios na condução das políticas sociais, particularmente as de saúde.

Sabe-se que a adesão do nível municipal à política pública influencia seu desempenho. Contudo, essa adesão não se restringe aos mecanismos institucionais internos à própria política (regras, incentivos, pactuações etc.); depende, também, do grau de adesão política dos prefeitos. Políticas descentralizadas podem ser mais ou menos permeáveis aos programas eleitorais e às opções ideológicas dos candidatos, e isso pode influenciar sua implementação. Considerando que, desde a Constituição de 1988, a política de saúde tem se pautado, em maior ou menor grau, pelos princípios da chamada Reforma Sanitária, que instituiu a universalização, o direito à saúde e criou o Sistema Único de Saúde (SUS), pergunta-se em que medida esses princípios têm sido incorporados pelos programas de governo dos candidatos a prefeito. Em outras palavras, quais são os compromissos dos candidatos a prefeitos com o SUS.
Este artigo apresenta alguns resultados da pesquisa 'Novos prefeitos e os compromissos do SUS', que teve como um de seus objetivos analisar as propostas de governo de prefeitos eleitos no ano de 2012, suas proposições para a política de saúde e para as políticas sociais. Para tanto, o artigo analisa as propostas dos prefeitos eleitos em 2012 e as confronta com documentos-base da gestão e da política municipal de saúde, a saber, os Relatórios das Conferências Municipais de Saúde e os Planos Municipais de Saúde de 24 municípios brasileiros selecionados nas cinco regiões do País.

O artigo expõe, a seguir, uma breve discussão sobre a descentralização na saúde e o papel dos municípios. Em sessão seguinte, relata os métodos da pesquisa, seguidos de seus resultados e conclusões.

\section{A descentralização do SUS e o papel da esfera municipal}

Ao se discutir descentralização, tem sido comum ter como objeto os casos das políticas de saúde e de educação, especialmente a partir de meados dos anos 1990, quando essas políticas foram municipalizadas, ou seja, quando os municípios passaram a ser os principais provedores de serviços.

O grau de descentralização e a forma como ela se dá são afetados pela dinâmica política e social interna a cada localidade, em que têm lugar relevante as pressões exercidas pela sociedade civil sobre o governo local e o próprio projeto político de cada gestão. A municipalização de políticas públicas se deu no Brasil de forma bastante desigual tanto pela diversidade de situações financeiras e capacidade administrativa dos municípios como pela vontade política de cada governo municipal de utilizar seus recursos na promoção de políticas públicas ou continuar solicitando auxílio das esferas estadual e federal para viabilizar ações de governo (ABRUCIO; FRANZESE, 2007). 
Dentre os aspectos que comprometem este quadro estão as contradições entre o desenho federativo brasileiro e o que se pode denominar 'federalismo da saúde', ou seja, o modo como o pacto federativo na saúde tem se caracterizado a partir da transferência de atribuições e responsabilidades para os municípios. Nesse contexto, surgem dilemas como o esvaziamento do papel dos estados vis-à-vis a centralização, em âmbito nacional, da formulação e indução das políticas.

Como contraponto ao aparente sucesso da efetivação do poder local a partir da municipalização, há também entraves importantes levantados por diversos autores:

(a) as políticas públicas são, particularmente, formuladas pelo nível federal e impostas às instâncias subnacionais.

Como afirma Arretche (2013), a União tem ampla competência legislativa e conta com autoridade regulatória para as políticas executadas pelos governos subnacionais. A interdependência revelou-se, quase sempre, como imposição centralizadora e por diversas vezes autoritária de uma força maior e praticamente acima do pacto federativo, qual seja, o governo federal.

(b) a descentralização produz uma fragmentação do poder sem necessariamente alterar de maneira positiva a alocação dos recursos públicos locais.

A baixa capacidade tributária dos municípios brasileiros é ainda maior sob o ponto de vista comparado (ABRUCIO, 2006). Oliveira (2006) afirma que o sistema tributário brasileiro gera elevada carga tributária (cerca de $35 \%$ do PIB), mas destoa de princípios importantes das finanças públicas: competitividade, equidade e simplicidade. Isso funciona como fator de desestímulo para o crescimento econômico e gera maior ônus às camadas da sociedade de menor renda, contribuindo para aumentar o processo de concentração de renda.

A proposta de construção da política de saúde impõe desafios à adoção de mecanismos de compensação das diferenças regionais que marcam a federação, o que seria possível a partir da constituição de novas relações fiscais e orçamentárias entre os governos. O atual modelo de federalismo fiscal, marcado pela política de estabilização econômica e contenção de gastos em saúde, acabou produzindo constrangimentos e ampliando os desequilíbrios já existentes entre os estados e municípios da federação (LIMA, 2008-2009).

Juntamente com as dimensões da política fiscal, é necessário reconstruir o modelo de federalismo. Para compensar as profundas disparidades existentes no País, também uma reforma tributária deveria contemplar a estruturação de um sistema de transferências compensatórias, visando assegurar um padrão mínimo de capacidade de gasto orçamentário para que os entes da federação possam atender às demandas da população por políticas públicas em condições menos desiguais (OLIVEIRA, 2006).

Rezende e Afonso (2004) afirmam também que a autonomia que se concedeu aos municípios com a Constituição não pôde ser plenamente exercida. Ainda que estudos empíricos mostrem que estados e municípios aumentaram o volume de recursos aplicados em atividades sociais como saúde e educação, a maior parte dos recursos financeiros necessários para melhorar a qualidade de vida vem das contribuições sociais arrecadadas pelo governo federal.

(c) a descentralização é também expressão de competitividade entre os entes federativos.

Desde a fundação da federação, as desigualdades regionais vêm sendo reforçadas pela existência de um número enorme de municípios pequenos, com baixa capacidade de sobreviver apenas com recursos próprios. 
Outra heterogeneidade constitutiva do federalismo brasileiro são as diferenças no processo de formação das elites locais no País e a forte rivalidade entre elas (ABRUCIO, 2006).

No plano fiscal, Rezende e Afonso (2004) acreditam que se deva buscar um equilíbrio entre competição e cooperação entre os entes no sentido de reduzir distâncias e competir para gerar eficiência e qualidade dos serviços públicos. Já Arretche (2002, P. 44), afirma que

nos estados federativos em que a política social está no centro dos mecanismos de legitimação política dos governos, a competição entre os estados tende a implicar expansão da oferta de serviços sociais.

Assim, as relações intergovernamentais não são inexistentes, mas altamente competitivas tanto vertical como horizontalmente, e marcadas pelo conflito, principalmente entre os que governam as grandes cidades e os que governam os estados. Nesse contexto, a instância mediadora tem sido o Supremo Tribunal Federal, a quem compete o controle da constitucionalidade. Porém,

suas ações não objetivam defender a autonomia dos estados frente à legislação federal, mas sim pedir o reconhecimento judicial sobre a inconstitucionalidade de decisões tomadas pelas assembleias constituintes estaduais. (SOUZA, 2005, P. 114).

Na saúde, as instâncias de pactuação já consolidadas garantem níveis razoáveis de cooperação entre os entes, dando maior estabilidade às regras institucionais setoriais. Essa pactuação é fundamental para superar as limitações do 'municipalismo autárquico', que 'incentiva a prefeiturização' e torna os prefeitos atores por excelência do jogo local e intergovernamental' (ABRUCIO, 2006), e para estimular uma das principais diretrizes do SUS, a regionalização, talvez a de implementação mais atrasada.
A mais recente iniciativa de institucionalização da regionalização, o Pacto pela Saúde, baseia-se no fortalecimento da pactuação política entre os entes federados e na diversidade econômica, cultural e social para a redefinição de regiões de saúde. Pode-se dizer, com base em Lima e Viana (2011), que o Pacto pela Saúde representa uma inflexão na forma de atuação do governo central e nas relações federativas no SUS, expressando o compromisso entre os gestores para o fortalecimento da gestão compartilhada do SUS ao acentuar a necessidade de cooperação intergovernamental na política de saúde e elevar o protagonismo dos estados e municípios na condução da regionalização. O Pacto pela Saúde melhorou as transferências diretas de recursos do nível federal para estados e municípios. Isso, contudo, não significou maior autonomia para os níveis subnacionais no uso de tais recursos, já que as transferências são para ações e programas específicos determinados previamente pelo nível central (MACHADO ET AL., 2014).

A pactuação setorial também não é capaz de eliminar a competição nas áreas fiscal e tributária, a dependência do nível federal e as recorrentes restrições financeiras, interferindo na eleição de prioridades pelos candidatos. Por outro lado, a lógica eleitoral às vezes impede a associação entre municípios de uma mesma região quando há oposição partidária entre prefeitos. Nesses casos, os gestores municipais criam serviços que poderiam ser otimizados se ofertados em associação com outros municípios, ou repassem serviços a organizações privadas, por vezes, atendendo também a interesses particularistas ou eleitorais, ou simplesmente não garantem os serviços necessários aos seus munícipes, fazendo com que a população procure por sua própria conta e risco os serviços de que necessitam em outras localidades. Essa lógica conta também com a persistência de práticas de cunho clientelista e de corrupção (FARAH, 2001).

É nesse contexto que ocorrem as opções 
locais de incorporação das diretrizes do SUS pelos prefeitos.

\section{Métodos}

$\mathrm{O}$ estudo adotou como procedimento metodológico a análise documental. A primeira fonte de dados foram as Propostas de Governo dos prefeitos eleitos no ano de 2012 para a gestão 2013-2016. Tais propostas foram confrontadas com o contexto da política de saúde do município por meio dos relatórios das Conferências Municipais de Saúde imediatamente anteriores ao pleito de 2012 e dos Planos Municipais de Saúde com vigência entre os anos de 2010 e 2013.

A Proposta de Governo é o documento no qual constam as principais orientações políticas, os compromissos e as medidas de governo. A partir das eleições municipais do ano de 2012, o Tribunal Superior Eleitoral passou a exigir o registro dos programas de governo dos candidatos e a disponibilizá-los em seu site (BRASIL, 2013).

Os relatórios das Conferências Municipais de Saúde expõem as negociações e disputas sobre os problemas, bem como as propostas para a política de saúde no âmbito local, e têm "importância como mediadores entre a Conferência e o cotidiano da formulação de políticas" (GUIZARDI ET AL., 2004, P. 17).

Já os Planos Municipais de Saúde, são a base para a execução, o monitoramento e a avaliação da gestão local de saúde. Os Planos se realizam a partir da análise situacional do município, da análise crítica dos dados epidemiológicos e das condições financeiras. Consideram-se também os determinantes e condicionantes de saúde e gestão da saúde. O Plano Municipal é o esforço para planejar a resposta dos municípios frente aos problemas de saúde na população que habita em seu território e deve estar em consonância com os Planos Estadual e Nacional de Saúde. De acordo ao Art. $2^{\circ}$ da Portaria 3.332/2006
(BRASIL, 2006), o Plano Municipal de Saúde é o instrumento que "apresenta as intenções e os resultados a serem buscados no período de quatro anos, expressos em objetivos, diretrizes e metas" ( $\left(1^{\circ}\right.$ do Art. $\left.2^{\circ}\right)$.

Selecionaram-se 24 municípios em todas as regiões do País. Para a seleção, adotou-se como critério de inclusão as capitais brasileiras - exceto as metrópoles - e os municípios com mais de 500.000 habitantes segundo o Instituto Brasileiro de Geografia e Estatística (IBGE). Dentre os municípios, foram excluídos os que não possuíam todos os documentos para análise: Belém, Porto Velho, Palmas, Aracaju, Feira de Santana, Nova Iguaçu, São Gonçalo, São José dos Campos, Sorocaba e Contagem. A seleção final incluiu: Boa Vista (RR); Rio Branco (AC); Jaboatão dos Guararapes (PE); Maceió (AL); Natal (RN); João Pessoa (PB); Teresina (PI); São Luis (MA); Cuiabá (MT); Campo Grande (MS); Goiânia (GO); Duque de Caxias (RJ); Campinas (SP); Guarulhos (SP); Osasco (SP); Ribeirão Preto (SP); São Bernardo do Campo (SP); Santo André (SP); Juiz de Fora (MG); Uberlândia (MG); Vitória (ES); Joinville (SC); Londrina (PR) e Florianópolis (SC).

Para analisar os documentos, foram selecionadas dimensões analíticas relevantes ao SUS a partir da literatura. Selecionaram-se as dimensões Reforma Sanitária, Financiamento, Integralidade, Regionalização, Participação Social, Intersetorialidade e Gestão do Trabalho e da Educação na Saúde. A cada dimensão corresponderam categorias e variáveis e temas que permitiram relacionar aspectos teóricos com os documentos selecionados. Um resumo dessa matriz encontra-se no quadro 1. As proposições dos documentos eram identificadas de acordo com as categorias e inseridas na matriz, uma para cada município. Para a apresentação dos resultados a seguir, os casos foram sistematizados para o conjunto dos municípios segundo cada uma das dimensões da pesquisa. 
Quadro 1. Matriz de análise dos documentos

\begin{tabular}{|c|c|c|}
\hline DIMENSÕES & CATEGORIAS & VARIÁVEIS e TEMAS \\
\hline Reforma Sanitária & $\begin{array}{l}\text { Democracia } \\
\text { Desigualdades, Igualdade, Inclusão } \\
\text { Direito à saúde } \\
\text { Acesso universal e público }\end{array}$ & $\begin{array}{l}\text { Inclusão social } \\
\text { Vulnerabilidades sociais } \\
\text { Universalização do acesso } \\
\text { Combate às desigualdades } \\
\text { Redistribuição } \\
\text { Direitos humanos } \\
\text { Democracia social } \\
\text { Solidariedade social } \\
\text { Sustentabilidade } \\
\text { Desenvolvimento sustentável } \\
\text { Meio ambiente saudável } \\
\text { Saúde e ambiente }\end{array}$ \\
\hline Financiamento & $\begin{array}{l}\text { Ampliação de recursos públicos } \\
\text { Transparência de recursos } \\
\text { Equilíbrio entre níveis de governo }\end{array}$ & $\begin{array}{l}\text { Cumprimento da Emenda } 29 \\
\text { Defesa de } 10 \% \text { para a saúde das despesas } \\
\text { federais correntes } \\
\text { Teto municipal } \\
\text { Co-financiamento estadual e federal } \\
\text { Aumento ou redução dos gastos municipais } \\
\text { Aumento de participação do setor privado } \\
\text { Orçamentos públicos }\end{array}$ \\
\hline \multirow[t]{3}{*}{ Integralidade } & Oferta de serviços & $\begin{array}{l}\text { Ampliação de cobertura de serviços } \\
\text { Ampliação da rede } \\
\text { Expansão da Estratégia Saúde da Família } \\
\text { Novos serviços específicos } \\
\text { Políticas de distribuição de medicamentos } \\
\text { Melhoria da Infraestrutura da rede } \\
\text { Accões prioritárias em prevenção: saúde do } \\
\text { idoso; controle do câncer de colo de útero e } \\
\text { de mama; e redução da mortalidade infantil e } \\
\text { materna } \\
\text { Fortalecimento da capacidade de respostas às } \\
\text { doenças emergentes e endemias, com ênfase } \\
\text { na dengue, hanseníase, tuberculose, malária e } \\
\text { influenza } \\
\text { Ações de promoção da saúde }\end{array}$ \\
\hline & Informatização do sistema & $\begin{array}{l}\text { Sistema de informação } \\
\text { Cartão SUS } \\
\text { Prontuário eletrônico }\end{array}$ \\
\hline & $\begin{array}{l}\text { Organização e hierarquização de } \\
\text { serviços }\end{array}$ & $\begin{array}{l}\text { Regulação do setor privado contratado } \\
\text { Regulação de leitos } \\
\text { Regulação de procedimentos } \\
\text { Territorialização } \\
\text { Contratualizaçãodo setor privado }\end{array}$ \\
\hline Regionalização & $\begin{array}{l}\text { Relação com outros municípios } \\
\text { Relação com nível estadual } \\
\text { Papel na região }\end{array}$ & $\begin{array}{l}\text { Consórcio de saúde } \\
\text { Região de saúde } \\
\text { Conselho gestor da região } \\
\text { ClB }\end{array}$ \\
\hline Participação Social & $\begin{array}{l}\text { Conselhos } \\
\text { Mobilização social } \\
\text { Orçamento participativo }\end{array}$ & $\begin{array}{l}\text { Infraestrutura para apoio do controle social } \\
\text { Outros mecanismos e instâncias de participa- } \\
\text { caão da sociedade civil } \\
\text { Mecanismos de informação ao usuário } \\
\text { Sistema de atendimento ao usuário }\end{array}$ \\
\hline Intersetorialidade & $\begin{array}{l}\text { Redes integradas de proteção social } \\
\text { Ações e programas nos determinan- } \\
\text { tes sociais da saúde }\end{array}$ & $\begin{array}{l}\text { Accões integradas com outras secretarias } \\
\text { Políticas e programas de ação nos determinan- } \\
\text { tes sociais }\end{array}$ \\
\hline $\begin{array}{l}\text { Gestão do Trabalho e da } \\
\text { Educação na Saúde }\end{array}$ & $\begin{array}{l}\text { Planejamento de gestão da força de } \\
\text { trabalho } \\
\text { Formação dos profissionais }\end{array}$ & $\begin{array}{l}\text { Previsão de concurso público } \\
\text { Redução dos vínculos precários } \\
\text { Planejamento de pessoal } \\
\text { Plano de cargos e carreiras } \\
\text { Instâncias de negociação com trabalhadores } \\
\text { da saúde } \\
\text { Cursos de capacitação profissional }\end{array}$ \\
\hline
\end{tabular}




\section{Resultados}

Na dimensão Reforma Sanitária, quase todos os municípios fazem proposições. Como era de se esperar, essas proposições estão mais nas Propostas de Governo e nas Conferências, dado o caráter mais político desses documentos, do que nos Planos de Saúde, devido ao seu caráter mais técnico. As diretrizes mais destacadas dizem respeito a sustentabilidade, ambiente sustentável e cidades saudáveis, temas relacionados à ideia de qualidade de vida. São temas mais presentes na agenda municipal do que democracia, desigualdades sociais ou participação. A categoria desigualdades sociais está mais presente por meio de proposições de inclusão social (geral ou de grupos reconhecidamente excluídos) ou de redução da pobreza. Há também a presença da defesa da integralidade e do SUS 'público', o que pode revelar conflitos internos à saúde e polêmicas entre candidaturas.

Outro aspecto relevante é a presença da humanização como diretriz social e para a saúde, presente principalmente nos Planos de Governo e Conferências. Essa presença indicaria a incorporação da humanização à política de saúde, ao menos no plano discursivo. Se essa incorporação estiver sendo adotada também nas ações concretas, representa uma atualização de fato dos princípios da reforma sanitária.

O financiamento, apesar de ser assunto crítico e complexo, não encontra, nos documentos municipais, a importância que tem na política setorial e na gestão do SUS. Em geral, o tema é evitado nas Propostas de Governo, que, quando mencionam o assunto, o fazem de forma geral, restrito à ampliação de recursos, sem especificar medidas ou diretrizes concretas ou o associam à transparência e ao uso probo de recursos e a problemas de gestão. As Conferências que tratam do tema indicam dilemas relevantes da reforma, principalmente a regulamentação da Emenda Constitucional 29
(EC 29), ainda na pauta quando a maioria delas foi realizada. Algumas criticam a DRU (Desvinculação dos Recursos da União) e a LRF (Lei de Responsabilidade Fiscal) ou defendem 10\% do PIB para a saúde, mas são poucas. Somente uma Conferência defendeu o ressarcimento ao SUS pelos planos privados de saúde.

Poucas também são as propostas que reivindicam renegociação dos tetos de financiamento federal e estadual. Apenas quatro municípios apresentam propostas ou reivindicações de recursos do nível estadual, em geral para serviços específicos. Chama a atenção haver um município onde a Proposta de Governo sugere contratar empresa para captar recursos e outro que propõe a expansão de serviços com o setor privado. Mas, em geral, os documentos não fazem proposições diretas à privatização ou mesmo terceirização de serviços, a não ser em aspectos da Gestão do Trabalho, que serão vistos mais à frente. Considerando que muitos municípios adotam esses mecanismos para a atenção à saúde, pode-se supor que reconhecê-los nos documentos de campanha ou de gestão não seja recomendável. As Conferências propõem, no limite, a associação com Organizações Não-Governamentais (ONGs) para serviços nas áreas de prevenção ou reabilitação.

Os medicamentos, ponto crítico do financiamento da saúde, só aparecem nos documentos de um único município, que sugere a ampliação de recursos para a assistência farmacêutica, tanto pelo próprio município como pelos outros níveis de governo, com ênfase para o nível estadual.

$\mathrm{Na}$ oferta de serviços, o padrão entre as Propostas de Governo é apresentar medidas de aumento de serviços, muitas por meio da construção de novas unidades. Chama a atenção que muitas das propostas de criação dessas novas unidades não constam dos respectivos Planos de Saúde e nem nas propostas das Conferências. Há municípios onde Planos e Conferências fazem propostas que 
aparentemente indicam razoável conhecimento e domínio de seus sistemas locais. Outros apresentam propostas muito gerais em relação a programas e políticas federais. Essa diferença poderia indicar graus diversos de institucionalização dos sistemas locais, assim como de autonomia ou dependência às políticas e ações federais.

Dentre os problemas mais indicados nos serviços, estão a dificuldade de acesso à média complexidade e a medicamentos. Dentre os 'novos' serviços, destacam-se proposições para a área de álcool e drogas, presente em muitos documentos, inclusive em diversas Propostas de Governo. De fato, mesmo considerando que as Propostas de candidatos contenham menos medidas objetivas e mais diretrizes gerais, ações de prevenção e recuperação em álcool e drogas são mais presentes que acesso a medicamentos e à média complexidade. De toda forma, vê-se que a ampliação do consumo de álcool e drogas e as lacunas assistenciais para lidar com este problema entraram na pauta dos governos municipais.

A produção dos registros e da informação em saúde continua sendo uma precariedade do sistema, já que muitas proposições nos documentos estudados destacam propostas antigas ainda ausentes em vários municípios, como a informatização das unidades e da própria rede, o prontuário eletrônico e o cartão SUS para todos os usuários.

A maioria dos municípios faz proposições para a regulação, principalmente nos Planos de Saúde e nas Conferências. Entretanto, apenas duas dentre as Propostas de Governo o fazem. Dentre as propostas contidas nos Planos, predominam a criação ou ampliação de centrais de regulação de leitos e de procedimentos de média complexidade, além da contratualização e regulação de prestadores públicos e privados. A fiscalização dos serviços de prestadores complementares também é muito citada pelas Conferências. Tais prioridades indicam que as fragilidades tradicionais na regulação já têm implicações para os recursos e para a efetividade do sistema, fazendo com que propostas de Planos de Saúde se aproximem daquelas das Conferências.

Mesmo onde há Complexos Reguladores, há proposições de expansão ou inclusão de novos serviços o que, em paralelo a algumas reivindicações de regulação total da rede, prevista em algumas Conferências, indica que as centrais de regulação ainda requerem muitos ajustes, mesmo nos municípios que aparentam ter sistemas mais organizados. Outra proposta muito comum é a de ampliação, criação ou implementação de sistemas de auditoria.

Essas propostas podem indicar amadurecimento dos sistemas municipais ao reconhecerem a necessidade de fazer valer ou criar mecanismos de controle sobre os serviços pagos pelo SUS, e há maior disponibilidade técnica para isso. Por outro lado, os problemas que causam a falta de regulação, como modalidades de negociação particularista ou dificuldades de pactuação entre municípios e nível estadual, que são recorrentes na estrutura do setor, não foram mencionados nos documentos analisados. A ausência de diagnóstico político para as fragilidades na regulação pode ser um impedimento à eficácia das soluções.

Pouco mais da metade dos municípios estudados trata da regionalização nos documentos analisados. É um número pequeno se considerados a importância dessa estratégia para a eficácia do SUS e os problemas para a sua efetiva implementação. Dentre as Propostas de Governo, apenas duas tratam do tema: uma delas, genérica, propõe a construção de espaço de cooperação regional para a gestão e outra, específica, de articulação regional para pacientes oncológicos.

A maioria das proposições relativas à regionalização vem das Conferências e Planos de Saúde, várias de forma vaga, indicando o aprimoramento da regionalização e ampliação de parcerias, outras com propostas de pactos para áreas específicas, especialmente 
urgências e emergências, ou para centrais regionais de regulação. Em alguns documentos, identificam-se propostas que podem estar relacionadas a possíveis conflitos em relação a procedimentos que recaem sobre municípios que são polo de atendimento, como ressarcimento de serviços e controle sobre os pactos na Programação Pactuada e Integrada (PPI). Há também proposições de criação de novos acordos e revisão da distribuição dos recursos na PPI de cada estado.

Chama a atenção a baixa presença do nível estadual nas propostas desse tema. É provável que a ausência ou mesmo a generalidade das proposições para a regionalização esteja relacionada às dificuldades dos diferentes contextos territoriais, sobre as quais os municípios têm baixa capacidade de intervenção. Desse modo, representaria uma ainda baixa efetividade dos pactos interregionais, principalmente em casos de municípios grandes e capitais aqui investigados. Outra possibilidade seria que, exatamente por seu tamanho e importância, esses municípios sejam os condutores da regionalização e as demandas por maior presença do nível estadual sejam mais fortes nos municípios com maior dependência. Nesse caso estaria em baixa a solidariedade requerida na estrutura federativa da saúde. Outra explicação seria a de que os Pactos estejam apresentando sucesso suficiente para retirar o tema das prioridades dos municípios. Essa probabilidade é menor, já que estudo abrangente e recente mostra a persistência de problemas nessa estratégia (LIMA ET AL., 2012).

Como esperado, a participação é enfocada em todas as Conferências e Planos de Saúde, mas menos da metade das Propostas de Governo trata do tema. Dentre estas, a maioria inclui diretrizes gerais para uma maior participação e apoio aos Conselhos. As medidas mais concretas são, em poucos casos, a adoção do orçamento participativo e, especificamente para a saúde, alguns propõem a criação de ouvidorias. Planos de Saúde e Conferências são similares nos aspectos gerais de estimular e respeitar os conselhos e a participação, propor capacitação de conselheiros e usuários, criar ou fortalecer ouvidorias e implantar ou aplicar a Política Nacional de Gestão Participativa do SUS.

Uma tendência das Conferências é propor a ampliação da participação na rede de serviços, com a implantação de novos conselhos locais e distritais, assim como conselhos em unidades de saúde, inclusive de prestadores privados ou filantrópicos, instituições que hoje não precisariam possuir, oficialmente, esferas de controle social. Outra área de proposições, também incluída em vários Planos de Saúde, é a de geração de informações para a população, com divulgação de indicadores territoriais de saúde e de serviços prestados e utilizados pela população, a serem divulgados pelas unidades de saúde.

Os conflitos existentes entre gestão e participação social não estão explícitos nos documentos, já que vários Planos incorporam as propostas das Conferências. Mas, por vezes, Conferências e Planos fazem propostas diferentes para diretrizes similares, o que indica, na realidade, baixa articulação entre gestão e sociedade civil. Maior articulação poderia ampliar esforços e economizar recursos em propostas consensuais. Por outro lado, há pouco registro das ações propostas que não foram conduzidas ou implantadas e o porquê, tanto por parte dos Planos como das Conferências, o que faz com que propostas antigas não adotadas fiquem em pé de igualdade com novas proposições.

A intersetorialidade está presente na maioria dos documentos dos municípios estudados, mas a maior parte das proposições adota a saúde como centro. Ou seja, a intersetorialidade é vista, na maior parte das vezes, como necessária para resolver problemas de saúde por meio de parcerias com outros órgãos, como educação e esportes, mas não necessariamente como estratégia de gestão local de políticas sociais. Alguns municípios apresentam propostas mais avançadas como 
fóruns de políticas sociais, de conselhos setoriais ou de seguridade social.

Chama a atenção o papel mais destacado dado hoje à assistência social, indicada por alguns documentos como prioridade de ação intersetorial com a saúde. De fato, é a assistência social quem mais se aproxima da saúde quanto a demandas sociais cotidianas da população. Destaque também para as áreas de habitação e mobilidade urbana que, mesmo com menor presença nos documentos, são indicadas como relevantes na relação com a saúde.

A gestão do trabalho é de fato um dos temas mais polêmicos do SUS hoje e os documentos expressam de alguma forma esses conflitos. Poucas Propostas de Governo tratam do tema e o fazem de forma geral, com diretrizes de valorização dos servidores, capacitação e educação permanente. Algumas, contudo, apresentam propostas mais concretas, como criação de escola de saúde, implantação de planos de cargos e carreiras. Três dessas propostas são mais ousadas ao propor a profissionalização por meio de avaliação e monitoramento de metas e resultados, com estrutura de incentivos e punições e implementação de protocolos de atendimento.

A educação permanente é a proposta mais frequente dentre todos os documentos, mas a maioria não inclui medidas concretas. Além de ações de educação permanente e da implantação da Política de Gestão do Trabalho e Educação Permanente, é comum a proposta de implantação ou efetivação de planos de cargos e salários. Planos e Conferências contêm muitas diretrizes similares, mas as medidas são distintas. O tema mais polêmico, sem dúvida, é o da contratação de pessoal. Enquanto a maioria das Conferências propõem concursos públicos e substituição de contratos precários, poucos Planos de Saúde o fazem. Nessa área, os Planos propõem seleções públicas e um dos municípios propõe a contratação por Organização da Sociedade Civil de Interesse Público (Oscip). Na Gestão do Trabalho, também não há evidências dos problemas que causam a precariedade do trabalho. Apenas em um dos municípios o documento da Conferência defende a superação das restrições impostas pela Lei de Responsabilidade Fiscal.

Os documentos em geral contêm propostas bastante circunscritas ao SUS. As políticas em vigor são frequentemente citadas pelos documentos, o que pode indicar maior unidade do sistema, capitaneada pelo nível federal. Nesse sentido, estaria valendo o preceito das responsabilidades dos distintos níveis de governo em relação ao SUS.

Ao mesmo tempo, o grau de apropriação e aprofundamento das propostas varia bastante entre os municípios, ressaltando dilemas entre a proposição de simetria no desenho institucional do SUS e a assimetria na distribuição do poder territorial e na sociedade brasileira.

Outro aspecto relevante diz respeito às diretrizes da descentralização e regionalização do sistema. Conforme mencionado acima, essa dimensão esteve presente de forma vaga e em documentos de poucos municípios, sugerindo que tais diretrizes não foram incorporadas às agendas municipais. Com isso, ressalta-se o desafio da constituição de uma visão cooperativa entre os municípios em detrimento da prevalência do caráter competitivo. Na prática, isto está presente tanto na disputa entre os municípios por dinheiro público como no repasse de custos a outros entes. Nesse aspecto, a questão da coordenação federativa e a formalização de canais de intermediação de interesses entre as esferas subnacionais e a nacional parecem ser central.

\section{Conclusões}

Os princípios da Reforma Sanitária e do SUS 
puderam ser apropriados pelos candidatos à gestão municipal? A análise das Propostas de Governo indica que o SUS foi, sim, incorporado pelas candidaturas, o que não quer dizer necessariamente adesão a seus princípios. Verifica-se que as Propostas apresentam diretrizes de ampliação e melhoria dos serviços e poucas contêm alternativas de privatização ou quebra da universalização.

A análise dos documentos das Conferências indica tendência de foco nos temas da saúde, em especial nos serviços e na rede de atenção. Essa tendência é compreensível, dada a abrangência de temas tratados pelo SUS hoje, todos se revertendo em políticas, programas e ações. E é também positiva, já que supõe um sistema consolidado e complexo, no qual a participação social tem papel central. Por outro lado, também representa um limite na politização dos temas que interferem na saúde, embora externos à agenda cotidiana do sistema.

\section{Referências}

\footnotetext{
ABRUCIO, F. L. Para além da descentralização: os desafios da coordenação federativa no Brasil. In: FLEURY, S. (Org.). Democracia, descentralização e desenvolvimento: Brasil \& Espanha. Rio de Janeiro: FGV, 2006. p. 77-125.
}

ABRUCIO, F. L.; FRANZESE, C. Federalismo e políticas públicas: o impacto das relações intergovernamentais no Brasil. In: ARAÚJO, M. F. I.; BEIRA, L. (Org.).

Tópicos de economia paulista para gestores públicos. São Paulo: FUNDAP, 2007.

ARRETCHE, M. Relações federativas nas políticas sociais. Educ. Soc., Campinas, v. 23, n. 80, p. 25-48, set. 2002.

Quando instituições federativas fortalecem o governo central? Novos estud. - CEBRAP, São Paulo, n.
Há, de modo geral, a incorporação da necessidade de efetivação do direito à saúde. Mas essa compreensão é especialmente representada pela ampliação da oferta de serviços no âmbito municipal. Tal apropriação pode expressar interesses que vão desde o compromisso dos prefeitos com o acesso da população às políticas sociais, até disputas do cenário eleitoral. Desse modo, a diretriz de municipalização, que se revelou a partir da descentralização da política de saúde, reforça a perspectiva democrática e de ampliação de direitos, mas impõe também novos desafios à efetivação da democracia nos planos municipal e nacional.

Mesmo diante de uma afirmação positiva sobre o SUS e em alguma medida sobre diretrizes da Reforma Sanitária, lidamos com um cenário de muitas dificuldades para a efetivação do direito à saúde. Essas dificuldades não são tratadas pelos documentos analisados, apenas suas possíveis soluções.

95, p. 39-57, mar. 2013.

BRASIL. Ministério da Saúde. Portaria 3.332, de 28 de dezembro de 2006. Aprova orientações gerais relativas aos instrumentos do Sistema de Planejamento do SUS. Brasília. Diário Oficial [da] República Federativa do Brasil, Brasília, DF, 2006. Disponível em: <http:// bvsms.saude.gov.br/bvs/saudelegis/gm/2006/ prt3332_28_12_2006.html>. Acesso em: 17 fev. 2016. Tribunal Superior Eleitoral. DivulgaCand: divulgação de registro de candidaturas 2012. Brasília, DF, 2013. Disponível em: < http://divulgacand2012.tse. jus.br/divulgacand2012/ResumoCandidaturas.action>. Acesso em: jul. 2013.

FARAH, M. F. S. Parcerias, novos arranjos institucionais e políticas públicas locais. RAP - Revista 
de Administração Pública, Rio de Janeiro, v. 35, n. 1, p. 119-145, jan./fev. 2001.

GUIZARDI, F. L. et al. Participação da comunidade em espaços públicos de saúde: uma análise das conferências nacionais de saúde. Physis, Rio de Janeiro, v. 14, n. 1, p. 15-39, jun. 2004.

LIMA, L. D. Federalismo fiscal e financiamento descentralizado do SUS: balanço de uma década expandida. Trab. Educ. Saúde, Rio de Janeiro, v. 6, n. 3, p. 573-597, nov. 2008/fev. 2009.

LIMA, L. D.; VIANA, A. L. A. Descentralização, regionalização e instâncias intergovernamentais no Sistema Único de Saúde. In:___ Regionalização e relações federativas na política de saúde do Brasil. Rio de Janeiro: Contra Capa, 2011.

LIMA, L. et al. Descentralização e regionalização: dinâmica e condicionantes da implantação do Pacto pela Saúde no Brasil. Ciênc. Saúde Coletiva, Rio de Janeiro, v. 17, n. 7, p. 1903-1914, jul. 2012.

MACHADO, C. V. et al. Federal funding of health policy in Brazil: trends and challenges. Cad. Saúde Pública, Rio de Janeiro, v. 30, n. 1, p. 187-200, jan. 2014.

OLIVEIRA, F. A. Reforma tributária: abrindo caminhos para o crescimento e para o fortalecimento da federação. In: FLEURY, S. (Org.). Democracia, descentralização e desenvolvimento: Brasil \& Espanha. Rio de Janeiro: FGV, 2006.

REZENDE, F.; AFONSO, J. R. A federação brasileira: fatos, desafios e perspectivas In: REZENDE, F.;

OLIVEIRA, F. A. (Org.). Federalismo e integração econômica regional: desafios para o Mercosul. Rio de Janeiro: FGV, 2004.

SOUZA, C. Desenho constitucional, instituições federativas e relações intergovernamentais no Brasil pós-1988. Rev. Sociol. Polít., Curitiba, n. 24, p. 105-121, jun. 2005.

\footnotetext{
Recebido para publicação em maio de 2015

Versão final em dezembro de 2015

Conflito de interesses: inexistente

Suporte financeiro: Centro Brasileiro de Estudos de Saúde (Cebes)
} 